\title{
Effect of timing for core preparation, luting cement type and root level on adhesion of fiber posts to intraradicular dentin
}

\author{
Sukuroglu, Elcin ; Aktas, Guliz ; Askın, Kerem ; Queiroz, José Renato Cavalcanti ; Özcan, Mutlu
}

DOI: https://doi.org/10.1080/01694243.2015.1115616

Posted at the Zurich Open Repository and Archive, University of Zurich ZORA URL: https://doi.org/10.5167/uzh-128068

Journal Article

Accepted Version

Originally published at:

Sukuroglu, Elcin; Aktas, Guliz; Askın, Kerem; Queiroz, José Renato Cavalcanti; Ȯzcan, Mutlu (2016). Effect of timing for core preparation, luting cement type and root level on adhesion of fiber posts to intraradicular dentin. Journal of Adhesion Science and Technology, 30(6):633-641.

DOI: https://doi.org/10.1080/01694243.2015.1115616 
Effect of timing for core preparation, luting cement type and root level on adhesion of fiber posts to intraradicular dentin

\section{Elcin Sukuroglu, DDS, $\mathrm{PhD}^{\mathrm{a}} /$ Guliz Aktas, DDS, $\mathrm{PhD}^{\mathrm{b}} /$ Kerem Askın, DDS, $\mathrm{PhD}^{\mathrm{c}}$ / José Renato Cavalcanti Queiroz, DDS, PhD ${ }^{d} /$ Mutlu Özcan, DDS, Dr.med.dent., PhD}

${ }^{a}$ Assistant Professor, Karadeniz Technical University, Faculty of Dentistry, Department of Prosthodontics, Sihhiye, Ankara, Turkey

${ }^{b}$ Assistant Professor, Hacettepe University, Faculty of Dentistry, Department of Prosthodontics, Sihhiye, Ankara, Turkey

${ }^{c}$ Assistant Professor, Hacettepe University, Faculty of Dentistry, Department of Endodontics, Sihhiye, Ankara, Turkey

${ }^{d}$ Assistant Professor, UnP Laureate University, Department of Biotechnology, Natal, Brazil

${ }^{a}$ Professor, University of Zurich, Dental Materials Unit, Center for Dental and Oral Medicine, Clinic for Fixed and Removable Prosthodontics and Dental Materials Science, Zurich, Switzerland

Short title: The effect of timing of core preparation and cement type on the fiber post adhesion.

Correspondance to: Prof. Dr. med. dent. Mutlu Özcan, University of Zürich, Dental Materials Unit, Center for Dental and Oral Medicine Clinic for Fixed and Removable Prosthodontics and Dental 
Materials Science, Plattenstrasse 11, CH-8032, Zürich, Switzerland. Tel: +41-44-63 45600, Fax: +41-4463 44305.e-mail: mutluozcan@hotmail.com

Abstract: This study assessed the effect of timing of core preparation and luting cement on adhesion of fiber reinforced composite (FRC) posts on different levels of intraradicular dentin when cemented with either conventional dual-polymerized or self-adhesive resin cement. Single-rooted human teeth $(\mathrm{N}=80)$ were endodontically treated and randomly divided into 2 groups ( $n=40$ ) according to resin cement: a) Conventional dual resin cement (Variolink II, V) or b) Self-adhesive resin cement (RelyX U200, R). They were further divided into two subgroups according to timing of core preparation ( $n=20)$ : a) immediate (i) or b) delayed (d). FRC posts (Cytec Blanco) were cemented and the roots were sliced into discs at the coronal, middle and apical levels. Push-out tests were then performed in a Universal Testing Machine $(1 \mathrm{~mm} / \mathrm{min})$. Data $(\mathrm{MPa})$ were analyzed using three-way ANOVA and Tukey`s tests considering the factors "core preparation time", "luting cement" and "root level" $(\alpha=0.05)$. Type of luting cement $(p<0.001)$, time of core preparation $(p<0.001)$ and root level $(p<0.001)$ significantly affected the bond strength results. $\mathrm{R}$ cement was more significantly affected by core preparation time (Ri: 2.91 $\pm 1.1 ; \mathrm{Rd}: 4.83 \pm 1.68)$ compared to $\mathrm{V}$ cement (Vi: $2.92 \pm 1.63 ; \mathrm{Vd}: 2.65 \pm 1.6)(p<0.05)$. Coronal region demonstrated significantly higher bond strength values than those of middle and apical third in all groups (coronal: $4 \pm 1.9$; middle: $3.1 \pm 1.4$; apical: $2.4 \pm 1.1)(p<0.05)$. Adhesive failure between cement and dentin was the most frequent (64\%) followed by adhesive failure between cement and post (18\%). Delayed core preparation can improve bond strength of FRC posts to intraradicular dentin when cemented with self-adhesive cement compared to conventional dual polymerized resin cement.

Keywords: Adhesion, fiber reinforced composite posts, intraradicular root, post-core, resin cement 


\section{Introduction}

Long-term success of a dental reconstruction on endodontically treated teeth is highly dependent on the amount of structural loss, adhesion and/or retention of the intraradicular posts in the canal, adhesion of the core to the post and preservation of coronal tooth tissue (ferrule effect) [1]. However, currently available clinical evidence shows the loss of retention of the post as the most frequent clinical failure in restored teeth using fiber reinforced composite (FRC) post and core $[2,3]$. Difficulties with moisture control and attenuated light into the root impair the bond strength of the cemented posts in the canal and more specifically the interface between the resin cement and intraradicular dentin [1]. Thus, laboratory studies evaluated different parameters in order to obtain a reliable adhesion between resin cement and dentin through which the lifespan of reconstructions on endodontically treated teeth restored FRC and core could be prolonged [1]. The effect of canal preparation [4], hybridization methods of root canal dentin [5], resin cement [5-17], polymerization methods for the resin cement [18], and post configuration $[6,19]$ have been studied and deemed to show effect on the bond strength of FRC posts. In fact, according to the clinical workflow, immediately after post cementation, the core is built up and it is prepared with rotating hand-pieces, which may cause torque forces to the newly cemented post until final polymerization reached.

When cast dowels are cemented, it is recommended not to trim the core immediately following cementation with zinc phosphate cement due to the fact that vibration originating from rotatory burs can reduce dowel retention [20]. However, this delayed core preparation is not followed by core build-up made of resin composite resin after cementation of the FRC post with resin luting 
cements. The foundation is generally prepared immediately due to favorable properties of the resin composite materials [21].

Clinical studies reported on early loss of retention due to FRC post dislodgement during the removal of the temporary restorations [22]. It is possible that disturbing the resin cement layer during the setting time due to the core preparation may cause decementation and eventually removal of the post [20]. In addition, recent studies showed that the degree of conversion and microhardness of the resin cements present statistically significant results within $24 \mathrm{~h}$ of setting irrespective of the polymerization modes employed [23,24] suggesting additional care during early occlusal adjustment of indirect restorations [23]. The main failure reason for FRC posts is loss of retention $[2,3]$ but due to many confounding factors, it cannot be identified whether core preparation time has an affect in this failure type $[25,26]$. It can be anticipated that rotating burs during core preparation before complete setting of the cement in the root canal may create torque forces yielding to shattering for the cement either from the intraradicular dentin or from the post surface but degree of polymerization and root conditioning may compensate for this factor [20].

The objectives of this study therefore to evaluate the effect of timing of core preparation and luting cement on adhesion of FRC posts on different levels of intraradicular dentin when cemented with either conventional dual polymerized or self-adhesive resin cement. The null hypotheses tested were that the type of resin cement, immediate or delayed core preparation would not affect the bond strength of FRC posts in

\section{Materials and Methods}

Specimens, bonding procedures

Recently extracted, caries-free human mandibular premolar teeth $(\mathrm{N}=80)$ were stored in distilled water with $0.1 \%$ thymol solution at room temperature until experiments. The inclusion criteria for the selected teeth were as follows: straight roots, round root canal form, absence of crown/root decay, cracks, previous endodontic treatment and root length of at least $16 \mathrm{~mm}$. 
Shapers System, Dentsply Maillefer, Tulsa, UK) with root canal preparation lubrication (Premier Dental Products), until the file F3 reached the working length ( $1 \mathrm{~mm}$ above the apical foramen) and irrigated with $5 \mathrm{~mL}$ of $2,5 \%$ sodium hypochlorite for 5 minutes. Prepared root canals were filled with gutta percha cones using the lateral condensation technique and $\mathrm{AH}$ Plus resin sealer (Dentsply, York, PA, USA). Then the coronal gutta-percha was removed from the root walls and the specimens were stored in physiological saline solution at $37^{\circ} \mathrm{C}$ for 7 days.

manufacturer's instructions of the post (Cytec fiber post). Only five preparations were made with each bur. Next, the root canals were water-rinsed and the excess moisture was removed with absorbent paper points before cementation of the FRC posts.

cement: a) Conventional resin cement (Variolink II, V) or b) Self-adhesive resin cement (RelyX U200, R). They were further divided into two subgroups according to timing of core preparation $(n=20):$ a) immediate: 10 minutes after post cementation (i) or b) delayed: $24 \mathrm{~h}$ storage in distilled water at $37^{\circ} \mathrm{C}(\mathrm{d})$.

Medental, Beijing, China; Adper Single Bond, 3M ESPE, St Paul, MN, USA). The resin cements were mixed and applied to the root canals using a lentulo-spiral instrument (Dentsply, Maillefer, Ballaigues, Switzerland). A glass FRC post ( $\varnothing: 1.4 \mathrm{~mm}$, Cytec Blanco) was introduced into the root canal under finger pressure and the excess luting cement was removed. The luting agent was then photo-polymerized with a halogen light-curing unit (Optilux 501, Kerr, Orange, CA, USA, light output: above $800 \mathrm{mw} / \mathrm{cm}^{2}$ throughout the experiments verified by a radiometer) for 40 s. In order to standardize the coronal portion of the cores, small size posterior transparent strip crowns for premolars were used (Tor Vm, Dental Manufacturing Company, Moscow, Russia).

carefully placed onto the post surface, and photo-polymerized for $40 \mathrm{~s}$ using a halogen light- 
curing unit from buccal, lingual, mesial and distal aspects in accordance with the manufacturer's instructions. The teeth were stored in $100 \%$ humidity at $37^{\circ} \mathrm{C}$ during the storage time. Each core foundation was prepared for 4 minutes (axially for $3 \mathrm{~min}$ and occlusally for $1 \mathrm{~min}$ ). Core trimming was performed according to the description of groups, using new diamond bur for each core preparation. Following trimming, the teeth were mounted in auto-polymerized acrylic resin blocks (Orthoresin, Dentsply/DeTrey, Kornstanz, Germany) and sectioned with a low-speed diamond blade (Isomet, 1000, Buehler Ltd.) under water-cooling to produce eight 1-mm thick post-dentin sections. The first three slices represented the coronal region (sections $1,2,3$ ), the next three the middle region (sections $4,5,6$ ), and the last two (sections 7,8 ) the apical region of the prepared post space. The thickness of each slice was measured using a digital caliper (0.01 mm accuracy; Mitutoyo, Tokyo, Japan).

Push-out test and failure analysis

Push-out test was performed using a cylindrical plunger mounted on the Universal Testing Machine (Model LRX-plus, Lloyd instruments Ltd., Fareham, UK). Compressive load was applied at a crosshead speed of $0.5 \mathrm{~mm} / \mathrm{min}$ until the post segment was dislodged from the root to the apical aspect in the apical-coronal direction. The plunger tip size was selected and positioned to contact only the post, without stressing the surrounding root canal walls.

surface of a cone, using the formula:

$S I=\pi(r+R) a$

where $\pi=3.14, R$ is the coronal radius, $r$ is the apical radius, $a$ is the apothem, computed using the formula:

$a=\left[h^{2}+(R-r)^{2}\right]^{1 / 2}$

where $\mathrm{h}$ is the thickness of the slice.

The debonded surfaces were examined using an optical microscope (Olympus SZ61, Tokyo, Japan) at x20 magnification in order to characterize the failure mode. Failures were classified as follows: AD: Adhesive failure along the interfacial region between the 
intraradicular dentin and the resin cement; AP: Adhesive failure along the interfacial region between the resin cement and the FRC post; C: Cohesive failure in the resin cement; and M: Mixed failure, adhesive failure along the interfacial region between the resin cement and dentin or FRC post together with cohesive failure in the resin cement.

Statistical Analyses

The means of each group were analyzed by three-way analysis of variance (3-way ANOVA) with push out bond strength (MPa) as the dependent variable and luting cement type (2 levels: conventional dual-polymerized versus self-adhesive cement), core preparation time (2 levels: immediate versus delayed) and root level (3 levels: coronal, middle, apical) as the independent factors (SPSS 15.0 software, IBM, Somers, NY, USA). Multiple comparisons were made by Tukey`s post hoc tests. $P$ values less than 0.05 were considered to be statistically significant in all tests.

\section{Results}

Type of luting cement $(p<0.001)$, time of core preparation $(p<0.001)$ and root level $(p<0.001)$ significantly affected the bond strength results (Table 2).

Regarding the resin cements irrespective of other parameters, $R$ cement $(3.8 \pm 1.7 \mathrm{MPa})$ presented significantly higher bond strength values compared to $\mathrm{V}$ cement $(2.8 \pm 1.6 \mathrm{MPa}$; Tukey`s test) (Table 3).

Regarding the time of core preparation, mean bond strength (MPa) was significantly higher in delayed groups $(3.7 \pm 1.9)$ compared to immediately prepared groups $(2.9 \pm 1.4$; Tukey`s tests $)$. R cement was more significantly affected by core preparation time ( $\mathrm{Ri}: 2.91 \pm 1.1 ; \mathrm{Rd}: 4.83 \pm 1.68)$ compared to $\mathrm{V}$ cement $(\mathrm{Vi}: 2.92 \pm 1.63 ; \mathrm{Vd}: 2.65 \pm 1.6)(p<0.05)$.

Coronal region demonstrated significantly higher bond strength values than those of middle and apical third in all groups (coronal: $4 \pm 1.9$; middle: $3.1 \pm 1.4$; apical: $2.4 \pm 1.1)(p<0.05)$.

AD type of failures was the most frequent failure type (64\%) followed by AP (18\%). Other failure types were either $M(13 \%)$ or $C$ type of failures $(5 \%)$. 


\section{Discussion}

This study was undertaken in order to evaluate the possible effect of immediate or delayed core preparation on the adhesion of FRC posts on different levels of intraradicular dentin when cemented with either conventional dual polymerized or self-adhesive resin cement. Since all parameters studied had a significant impact on the results, the null hypothesis is rejected.

The commonly recommended protocol for adhesion of FRC posts in the root canal requires conditioning the intraradicular dentin with etch-and-rinse adhesive systems followed by cementation of the post with conventional dual-polymerized resin cements [1,27]. Yet, meticulous application of all steps is required to achieve reliable adhesion of the FRC post [1]. In order to simplify the clinical procedures and eliminate possible errors during conditioning of the dentin and the post, self-adhesive resin cements have been suggested that do not require any preliminary conditioning protocol. Several bond strength test methods (i.e. microtensile, pull-out and push-out tests) have been performed to evaluate FRC post retention to intraradicular dentin. Nevertheless, the push-out test has proven to be the most efficient and reliable method $[28,29]$. Accordingly, the thin slice micro-push out test was performed in this study.

According to the available evidence, no consensus seems to be present regarding to pushout bond strength of resin cements in relation to the root level. While some recent studies have reported that root canal region does not affect the bond strength to intraradicular dentin $[28,30]$, others reported decreased bond strength values in the the apical region $[31,32]$. In this study, the lowest mean bond strength values were achieved in the apical region. This finding could be attributed to the insufficient photo-polymerization of the cements at the apical one third [33]. On the contrary, coronal region demonstrated significantly higher bond strength values when compared with middle and apical one third in both cement groups, which is in agreement with several other studies $[34,35]$. One possible explanation for the high bond strength for coronal region may be that this region is easier to etch and apply adhesive resin when total etch 
technique is used. Other reason is the high light attenuation and better moisture control compared to the deep parts of the root canal $[36,37]$. On the other hand, low bond strengths obtained in the apical region does not necessarily be related to the time of core preparation as less torque effect could be affected in this region. Thus, the low results are highly due to limited amount of polymerization at the apical region.

With the use of self-adhesive resin cements procedural errors could be avoided [1] but limited information is available on the adhesion of FRC posts with such cements. The literature presents conflicting results concerning the efficacy of self-adhesive cements versus conventional dual-polymerized ones $[6,8,12-14]$. However, in general, using an etch-and-rinse approach for conditioning the intraradicular dentin presented better results for both selfadhesive $[6,8,12-14]$ and conventional resins $[5,9,10,16,17]$, while in some studies no significant difference was found between them $[6,17]$. It has to ne noted that these studies evaluated bond strength results only $24 \mathrm{~h}$ after cementation and/or following some type of aging at the bonded interface such as water storage or thermo and/or mechanical cycling. Moreover, the core build up was not performed prior to the push-out test $[5,10,12,14,17]$ or when core applied no information was provided whether the core was prepared immediately or after some time $[6,8,13]$. Previous studies suggest that clinical procedures such as occlusal adjustment or core preparation prior to complete setting time of the resin cement $(24 \mathrm{~h})$ could generate stress at the resin cement interfaces, reducing bond strength results [23]. Only Sadek et al [7] compared bond strengths using the push-out test after immediate or delayed preparation following cementation, and their study indicated that conventional resin cements (AllBond 2/Duo Link) presented better results than that of self adhesive cement (RelyX Unicem) for both preparation times, which is contradictory to our results. One important distinction must be highlighted, however that no reference regarding the time of core preparation was mentioned in this study [7].

Qualitatively, failure analysis showed that both $\mathrm{V}$ and $\mathrm{R}$ cements after delayed core preparation presented less number of adhesive failures than immediately prepared groups 
where adhesive failures were at both cement-dentin and cement-post interfaces. However, in the push-out test due to the difference in specimen preparation time which may add up from to several minutes to hours, an additional degree of conversion over $24 \mathrm{~h}$ can affect the mode of failure. Thus, it was not possible conclude whether these results were only due to core preparation time. This could be considered as one limitation of this study.

The increase in bond strength after delayed core preparation was only verified in the $R$ cement groups. The difference in the polymerization chemistry of these resin cements could explain the results. Previous studies showed that the initial degree of conversion for $\mathrm{R}$ cement is lower than conventional dual polymerized one (Duolink). This difference however decreased after $6 \mathrm{~h}$ [38]. It could be important given that a difference of $4 \%$ was noted in degree of conversion that could affect the physical properties of resin composites. Additionally, regarding the bulk of $\mathrm{R}$ cement, reactions between the filler and/or basic components with acidic monomers during setting time neutralize the $\mathrm{pH}$, promoting some expansion of the bulk material [27]. The effect of the degree of conversion and $\mathrm{pH}$ neutralization in self-adhesive cements on the immediate and $24 \mathrm{~h}$ delayed bond strength results need to be evaluated to confirm these assumptions. The absence of these chemical characterizations and use of only two resin cements in non-aged conditions are limitations of this study.

\section{Conclusions}

From this study, the following could be concluded:

1. Improvement in the push-out bond strength of FRC post using a delayed core preparation is resin cement dependent and self-adhesive cement benefitted more then conventional dualpolymerized resin cement.

2. Regardless of the cement type, adhesion of the FRC post especially in the apical one third of the roots was poor.

\section{Clinical Relevance}


When FRC posts are cemented with self-adhesive cement in the root canal, core preparation should be delayed $24 \mathrm{~h}$ in order not to impair the adhesion of the post to the intraradicular dentin.

\section{Conflict of interest}

The authors did not have any commercial interest in any of the materials used in this study.

\section{References}

1. Goracci C, Ferrari M. Current perspectives on post systems: a literature review. Aust Dent J. 2011;56:77-83.

2. Rasimick BJ, Wan J, Musikant BL, Deutsch AS. A review of failure modes in teeth restored with adhesively luted endodontic dowels. J Prosthodont. 2010;19:639-646. 
3. Naumann M, Koelpin M, Beuer F, Meyer-Lueckel H. 10-year survival evaluation for glassfiber-supported postendodontic restoration: a prospective observational clinical study. J Endodont. 2012;38:432-435.

4. Coniglio I, Carvalho CA, Magni E, Cantoro A, Ferrari M. Post space debridement in ovalshaped canals: the use of a new ultrasonic tip with oval section. J Endodont. 2008;34:752-755.

5. Calixto LR, Bandeca MC, Clavijo V, Andrade MF, Vaz LG, Campos EA. Effect of resin cement system and root region on the push-out bond strength of a translucent fiber post. Oper Dent. 2012;37:80-86.

6. Bitter K, Meyer-Lueckel H, Priehn K, Kanjuparambil JP, Neumann K, Kielbassa AM. Effects of luting agent and thermocycling on bond strengths to root canal dentine. Int Endodont J. 2006;39:809-818.

7. Sadek FT, Goracci C, Monticelli F, Grandini S, Cury AH, Tay F, et al. Immediate and 24-hour evaluation of the interfacial strengths of fiber posts. J Endodont. 2006;32:1174-1177.

8. Kececi AD, Ureyen Kaya B, Adanir N. Micro push-out bond strengths of four fiber-reinforced composite post systems and 2 luting materials. Oral Surg Oral Med Oral Pathol Oral Radiol Endod. 2008;105:121-128.

9. Radovic I, Mazzitelli C, Chieffi N, Ferrari M. Evaluation of the adhesion of fiber posts cemented using different adhesive approaches. Eur J Oral Sci. 2008;116:557-563.

10. Bitter K, Paris S, Pfuertner C, Neumann K, Kielbassa AM. Morphological and bond strength evaluation of different resin cements to root dentin. Eur J Oral Sci. 2009;117:326-333.

11. Giachetti L, Grandini S, Calamai P, Fantini G, Scaminaci Russo D. Translucent fiber post cementation using light- and dual-curing adhesive techniques and a self-adhesive material: push-out test. J Dent. 2009;37:638-642.

12. Mazzoni A, Marchesi G, Cadenaro M, Mazzotti G, Di Lenarda R, Ferrari M, et al. Push-out stress for fibre posts luted using different adhesive strategies. Eur J Oral Sci. 2009;117:447453. 
13. Leme AA, Coutinho M, Insaurralde AF, Scaffa PM, da Silva LM. The influence of time and cement type on push-out bond strength of fiber posts to root dentin. Oper Dent. 2011;36:643648.

14. Bitter K, Eirich W, Neumann K, Weiger R, Krastl G. Effect of cleaning method, luting agent and preparation procedure on the retention of fibre posts. Int Endodont J. 2012;45:1116-1126.

15. Dimitrouli M, Geurtsen W, Luhrs AK. Comparison of the push-out strength of two fiber post systems dependent on different types of resin cements. Clin Oral Investig. 2012;16:899-908.

16. Soares CJ, Pereira JC, Valdivia AD, Novais VR, Meneses MS. Influence of resin cement and post configuration on bond strength to root dentine. Int Endodont J. 2012;45:136-145.

17. Sterzenbach G, Karajouli G, Naumann M, Peroz I, Bitter K. Fiber post placement with core build-up materials or resin cements-an evaluation of different adhesive approaches. Acta Odontol Scand. 2012;70:368-376.

18. Giachetti L, Scaminaci Russo D, Baldini M, Bertini F, Steier L, Ferrari M. Push-out strength of translucent fibre posts cemented using a dual-curing technique or a light-curing self-adhering material. Int Endodont J. 2012;45:249-256.

19. Coniglio I, Magni E, Cantoro A, Goracci C, Ferrari M. Push-out bond strength of circular and oval-shaped fiber posts. Clin Oral Investig. 2011;15:667-672.

20. Soares JA, Brito-Junior M, Fonseca DR, Melo AF, Santos SM, Sotomayor Ndel C, et al. Influence of luting agents on time required for cast post removal by ultrasound: an in vitro study. J Appl Oral Sci. 2009;17:145-149.

21. Zarow M, Devoto W, Saracinelli M. Reconstruction of endodontically treated posterior teeth-with or without post? Guidelines for the dental practitioner. Eur J Esthet Dent. 2009;4:312-327.

22. Monticelli F, Grandini S, Goracci C, Ferrari M. Clinical behavior of translucent-fiber posts: a 2-year prospective study. Int J Prosthodont. 2003;16:593-596.

23. Arrais CA, Giannini M, Rueggeberg FA. Kinetic analysis of monomer conversion in autoand dual-polymerizing modes of commercial resin luting cements. J Prosthet Dent. 2009;101:128-136. 
24. Yan YL, Kim YK, Kim KH, Kwon TY. Changes in degree of conversion and microhardness of dental resin cements. Oper Dent. 2010;35:203-210.

25. Van Meerbeek B, Peumans M, Poitevin A, Mine A, Van Ende A, Neves A, et al. Relationship between bond-strength tests and clinical outcomes. Dent Mater. 2010;26:e100-121.

26. Ferracane JL. Resin-based composite performance: are there some things we can't predict? Dent Mater. 2013;29:51-58.

27. Ferracane JL, Stansbury JW, Burke FJ. Self-adhesive resin cements - chemistry, properties and clinical considerations. J Oral Rehabil. 2011;38:295-314.

28. Goracci C, Tavares AU, Fabianelli A, Monticelli F, Raffaelli O, Cardoso PC, et al. The adhesion between fiber posts and root canal walls: comparison between microtensile and pushout bond strength measurements. Eur J Oral Sci 2004;112:353-361.

29. Soares CJ, Santana FR, Castro CG, Santos-Filho PC, Soares PV, Qian F, et al. Finite element analysis and bond strength of a glass post to intraradicular dentin: comparison between microtensile and push-out tests. Dent Mater. 2008;24:1405-1411.

30. Foxton RM, Nakajima M, Tagami J, Miura H. Adhesion to root canal dentine using one and two-step adhesives with dual-cure composite core materials. J Oral Rehabil. 2005;32:97-104.

31. Bouillaguet S, Troesch S, Wataha JC, Krejci I, Meyer JM, Pashley DH. Microtensile bond strength between adhesive cements and root canal dentin. Dent Mater. 2003;19:199-205.

32. Mallmann A, Jacques LB, Valandro LF, Mathias P, Muench A. Microtensile bond strength of light- and self-cured adhesive systems to intraradicular dentin using a translucent fiber post. Oper Dent. 2005;30:500-506.

33. Acquaviva PA, Cerutti F, Adami G, Gagliani M, Ferrari M, Gherlone E, et al. Degree of conversion of three composite materials employed in the adhesive cementation of indirect restorations: a micro-Raman analysis. J Dent. 2009;37:610-615.

34. Ferrari M, Mannocci F, Vichi A, Cagidiaco MC, Mjor IA. Bonding to root canal: structural characteristics of the substrate. Am J Dent. 2000;13:255-260. 
35. Zicari F, Couthino E, De Munck J, Poitevin A, Scotti R, Naert I, et al. Bonding effectiveness and sealing ability of fiber-post bonding. Dent Mater. 2008;24:967-977.

36. Kremeier K, Fasen L, Klaiber B, Hofmann N. Influence of endodontic post type (glass fiber, quartz fiber or gold) and luting material on push-out bond strength to dentin in vitro. Dent Mater. 2008;24:660-666.

37. Navarra CO, Goracci C, Breschi L, Vichi A, Corciolani G, Cadenaro M, et al. Influence of post type on degree of conversion of a resin-based luting agent. Am J Dent. 2012;25:17-20.

38. Frassetto A, Navarra CO, Marchesi G, Turco G, Di Lenarda R, Breschi L, et al. Kinetics of polymerization and contraction stress development in self-adhesive resin cements. Dent Mater. 2012;28:1032-1039. 


\section{Captions to legends:}

\section{Tables:}

Table 1. Brands, types, chemical composition, manufacturers and batch numbers of the resin cements used in this study.

Table 2. Number of specimens, mean push-out strength and significant effect of root level on the results (Tukey`s test).

Table 3. Push-out bond strength results of FRC posts cemented with either conventional resin cement (Variolink II, V) or self-adhesive resin cement (RelyX U200, R) after immediate (i) and delayed $(d)$ core preparation, at the coronal $\left(1^{\text {st }}\right)$, middle $\left(2^{\text {nd }}\right)$ and apical $\left(3^{\text {rd }}\right)$ root level and failure types (AD: Adhesive failure along the interfacial region between the intraradicular dentin and the resin cement; AP: Adhesive failure along the interfacial region between the resin cement and the FRC post; C: Cohesive failure in the resin cement; and M: Mixed failure, adhesive failure along the interfacial region between the resin cement and dentin or FRC post together with cohesive failure in the resin cement). 
